\title{
Case of Green Land International School Community-Based Work in Imbaba, Egypt: A Success Story of Corporate Social Responsibility
}

\author{
Aya Maher \\ German University in Cairo (GUC) Faculty of Management Technology, \\ El-Tagamoa El Khames, New Cairo City, Cairo, Egypt
}

\begin{abstract}
Greenland International School is an International Baccalaureate (IB) school started by an Egyptian elite group of young parents in 1994. The school first started with a few kindergarten classes in a small rented villa in Cairo's high-class district of Mohandessin.
\end{abstract}

As time passed, the small villa was no longer able to accommodate for the increasing inflow of children, meanwhile, the owners also wanted to expand the kindergarten classes to offer a full service program for preparatory and secondary schooling. This need obviously obligated the establishment of newer and bigger premises for Greenland. However, finding an affordable location with reasonable distance from Mohandessin was nothing but an easy task for the owners, especially at a time when real-estate and land prices were considered to be at their maximum.

Three years later, precisely in September 1997, the school's building was established in Geziret Mohamed; a poor neighborhood of the underprivileged district of Imbaba. Although this location was accompanied by many challenges, it was chosen because of primarily two reasons: firstly, because of the proximity of distance to Mohandessin and to Greenland kindergarten, (where many parents send their children already), and secondly because of the affordable price per square meter of land. Not only the school's owners believed that Geziret Mohamed is a good deal with regards to price and distance, but also and more importantly, they saw a nurturing environment in which they could establish community-based work as a fundamental part of education in Egypt.

In 2004, the school's administration founded the Green Land Charity Association with a starting capital of 35,000 Egyptian pounds collected from the donations of the school's shareholders, aiming to implement eight environmental, educational and health development non-profitable projects in Geziret Mohamed. This study takes the 'Mostwasaf project' as an example of an award-winning community service project undertaken by Greenland students. This project was aimed at renovating, cleaning and equipping a small local hospital all by mere efforts of Greenland students. It received 'The 2007 Robert Blackburn International Award' for the best community service project among 2167 IB schools in 125 countries and attended by 582,000 students from different nationalities. (GPIS, 2007-2008).

This case focuses on analyzing the community-based initiative introduced by the school's staff and students. It also takes a close look at their management process for renovating and restoring the small charity hospital serving the community. The purpose of this study is to highlight the main lessons learnt that could serve as a model for business and corporations to follow in other poor and

Copyright (C) 2012 Aya Maher. This is an open access article distributed under the Creative Commons Attribution License unported 3.0, which permits unrestricted use, distribution, and reproduction in any medium, provided that original work is properly cited. Contact author: Aya Maher E-mail: aya.ahmedmaher@guc.edu.eg 
deprived areas in the MENA region. This model is believed to help businesses and corporations realize a sustainable approach to development in a win-win relationship with the local community.

Keywords: Egypt, Education, Social Responsibility, NGO, Charitable Projects, Poverty, Healthcare, Greenland, International Baccalaureate, IB, community work, team work, human resource management, leadership, motivation.

\section{Introduction}

It was a hot afternoon on Sunday, August 15 2011, when Architect Mokhtar Mokhtarfounder and managing director of Greenland Nursery School- and his wife, Francoise head of educational services- were driving from Greenland nursery on Lebanon street to Geziret Mohamed in Giza, Egypt.They both started to remember their first drive to check the location 17 years ago when they both had set their stopwatch to calculate the exact trip duration, and how closely they watched the surroundings.

They recalled when Francoise started to feel dizzy from the repeated bumpings on the unpaved road. Back then, She was thinking about the challenges they still have ahead in order to find a suitable location for the school, when suddenly Mr. Mokhtar pulled the brakes; a cow unexpectedly appeared out of nowhere and was crossing the street. "Oh my god, and this is where our buses will drive everyday!", She told her husband.

Both Mokhtar and Francoise had their concerns about building their school in such a district when almost all the school's children, parents and staff were from the elite community of Mohandessin. They were worried about the very poor conditions of the residents of the neighborhood of Imbaba surrounding the school and how would they accept their new neighbors. They knew that the area might be hostile to new investments, but despite all the challenges, they still saw a promising opportunity.

\section{Background}

\section{The Young Parents Dream}

The idea of Greenland School first started in 1993 by an elite group of highly educated young Egyptian parents in their late 20s and early 30s who had one thing in common: they were worried about the future of their children's education. They all had young children at the age of nursery (preschoolers) and lived in the posh district of Mohandessin (a classy area in Cairo, Egypt) and most of them were unsatisfied by the quality of education the schools offered.

Those young parents always met to discuss their plans for their children's schools. They all dreamt about a unique educational experience in which their children would learn and help people learn. They were also very keen that their children preserve their own Egyptian identity.

In March 1993, after one of the meetings attended by nearly fifty friends and acquaintances; Mokhtar, who was a midthirties bright architect and a father of two children, discussed with his friends the necessity to start a school offering the best quality of education in a healthy environment focusing on Egyptian ethics and values. Few weeks later and after several meetings in Mokhtar's house, the group of parents agreed to pursue their dream by starting a nursery school. 
They agreed on the capital needed and the shares of each member and commenced the feasibility studies for the project. Within few months, a new company was established consisting of a total of 40 partners who chose Greenland Pre vert for the school's name, and it was agreed to have a French section in addition to the English section.

\section{The Dreams Become True}

In January 1994, the group succeeded in renting a small villa in the center of Mohandessin district in Cairo. Mr. Mokhtar was nominated to be the chairman and managing director of the nursery assisted by his wife, Madame Francoise. Mokhtar and Francoise were well-known among the group for their leadership abilities and organizational skills. They soon assembled a team of professionals including administrators, teachers and nurseryeducation specialists. The whole team was motivated, enthusiastic and worked around the clock to get everything ready before the official opening day of the nursery in September of that year.

After years of extreme hard work and dedication, Greenland nursery realized great success; it had become widely reputed for its high quality service and very dedicated staff. The nursery was also doing very well in terms of revenues so the shareholders considered expansion of the Greenland project to build a new school and continue their dream of providing the best education possible.

\section{Greenland School}

\section{Setting the Stage}

By that time, the shareholders realized that the new school could not be built in the same district as the nursery which became very crowded with children and staff. They had to look for another location. After six month of intensive search by Mokhtar and some of the shareholders for a near location that is not far from the nursery in Mohandessin,
Mokhtar finally found a spacious piece of land that is suitable for the school in Geziret Mohamed area which was considered the nearest possible area to the nursery in Mohandessin. In light of the incredibly expensive rental fees and the proximity of the distance between Geziret Mohamed and Mohandessin, and despite the many challenges they knew they would face, Mokhtar and the group decided that Geziret Mohamed was the best of their options in terms of price and location.

Nevertheless, both Mokhtar and Francoise knew that they have a big challenge ahead of them. In such an underprivileged area that is hostile to new investments, they knew that they needed to do a tremendous amount of effort to absorb the resentment of the impoverished locals to the newly founded elite school and its students. Would they accept these seemingly well-off students and teachers as their neighbors? And what could Greenland do as a contribution to help the local community?

\section{Geziret Mohamed, Imbaba}

Imbaba's population was estimated to be around one million people. The majority of the population were living under poverty line in dilapidated houses. The small canal that ran through the district was polluted with rubbish and dead animals, the houses and local schools were derelict, and it was clear that the people in the area were leading a very difficult life. The local government failed to solve many of the local community problems due to budget constraints, but on the other hand, it promoted real-estate investment in the area. There were huge spaces of un-used land and the government urged investors to capitalize on it. It presented incentives, convenient payment schemes and tax holidays.

In this context, Mokhtar met with the board of directors to discuss the issue of improving the conditions of the area. Engineer Tarek Ezzat, one of the school shareholders, described Gezirat Mohamed to be one of the 
poorest and most underprivileged rural places in Giza governorate; with high unemployment and high levels of pollution.(Ezzat, 2012). May Wali, who is also one of the partners and the administration manager of the school nursery, mentioned that on the way to Gezirat Mohamed, one could see the remains of dead animals on the sides of the road, she also added that diseases such as Bilharzias was widely spread in the area due to the unhygienic conditions of the surrounding environment (Wali,2011). Another board member, Lamia Khalifa who was also a supervisor at the nursery, added that the village lacked proper infrastructure, such as proper sewage system and electric supply. She also added that the people of Gezirat Mohamed were forced to throw their garbage in the canal streams as it costs them less than ordering a garbage company to collect it. (Khalifa, 2011).

By that time, with all these ugly facts laid on the tables, all patrons had already known that they bear part of the responsibility for improving the conditions of the impoverished locals in Geziret Mohamed.

\section{The International Baccalaureate (IB) system}

It was a hot day in September 1997, and the new Greenland Pre Vert International School (GPIS) building was ready. Teachers and staff were recruited for the school and all partners joined the school's official inauguration. It was a great relief for the whole team to see Greenland's opening a success after all the hard work done in previous months, racing against time to be ready for this day. Among the staff there were more than ten employees from the local residents (one of the important benefits the school has brought to the area was job creation.)

After a couple of years of hard work and success, both Mokhtar and Francoise decided to accredit the school with the International Baccalaureate (IB) system to elevate the school to the international level and to fulfill their plans in helping the poor community of
Gezirat Mohamed. The IB system was chosen specifically because it encourages students to undertake community work initiatives. The International Baccalaureate Educational system or (IB) is a non-profit organization that was established in 1968 and currently works within at least 3,300 schools in 141 countries, believing that today's learners are tomorrow's leaders who should develop the intellectual, personal, emotional and social skills to live in this world and globalize.

The IB system is divided into three programs, the first: PYP, refers to 'Primary Years Program' and involves students between the ages of 3 to 12 . The second: MYP, refers to 'Middle Years Program' and involves students between the ages of 13 to 16, and finally the DP which refers to 'Diploma Program', this involves students between 16 and 19 years old. The MYP system-- the Middle Years Program-- is keen to develop a basic entity in the student's mindset to the areas of interaction, and the most important of the five areas of interaction is the community and service. These areas of interactions are embedded in the subjects they take in the middle year's program so that the students develop it naturally. (IBO, 2011).

\section{Corporate Social Responsibility}

With time, and as the years went by, the social responsibility of the school shareholders, managers, staff, parents and students increased, as each time they traveled back and forth to the school, they could see the contrast with their own lives, as they watched the poverty and the modest conditions of the locals through the windows. Parents were regularly informed by the school about charitable activities and fund raising events for the local community. They all realized the need and the value of helping the poor in this community through these charitable projects, and they also told their families and friends, believing that awareness encouraged more people to give generously. 


\section{The Greenland Charity Association}

Another factor that also helped increase the awareness for the community activities as years went by was the high social responsibility of the shareholders of the school, who were concerned not only with the well-being of their children's education, but also with helping those in need through charitable projects in the fields of education, healthcare and the environment (GPIS, 2008). In 2004, the school partners decided to establish the Green Land Charity Association with a starting capital of 35,000 Egyptian Pounds, collected from the donations of the partners and aiming at implementing eight developmental nonprofitable projects in Geziret Mohamed; environmental, educational and health projects. The environmental project included collecting rubbish, recycling, paving roads, planting trees and transforming dumps into green spaces. The educational project included illiteracy eradication, vocational training for unemployed youth and provision of some government schools with needed educational material to improve their educational process. The health projects aimed at offering continued support for a small charitable hospital or 'Mostawsaf' (Arabic translation for clinic) (GPIS, 2008).

\section{The 'Mostawsaf' Project}

The school initiated a health project or the 'Mostawsaf Project' which was aimed at offering sustainable support for a small charity hospital. The students decided to work on the health care unit or the 'Mostawsaf Project' in the area around the school. The Mostawsaf lacked all the necessary equipment, however, the students managed to collect some money from bake sales, garage sales, baby-sitting and car washing. They succeeded in rebuilding, cleaning and furnishing the Mostawsaf including the administration and patients' rooms, the pharmacy, the surgery rooms, the cafeteria and the kitchen (GPIS, 2008). Omar Ezzat, an MYP student, participated in this project in the school year 2007-2008 and recounts his experience. "We undertook this project due to our feeling of having a social responsibility towards our community, that we should be a positive contributor to it, and that we should thrive to push it forward and improve other people's standard of living. It took a lot of effort from us, but we were repaid well. The whole idea started under the theme of 'Being Positive' (Ezzat, 2012).

The Mostawsaf project received 'The 2007 Robert Blackburn International Award' for the best community service project among 2167 IB schools in 125 countries and attended by 582,000 students from different nationalities.

\section{Students' Management Process for the Mostawsaf Project}

\section{Defining Objective}

Before starting the Mostawsaf (Clinic) project, students were asked to come up with their objectives as groups and teams for the expected added value of the 'Mostawasf project' under the theme of 'Being Positive'. Students reported 14 different benefits (an example of what they said was: 1- To get trained to be responsible and positive, 2. To encourage others to do like us. 3 . To work on their profile...etc.) (GPIS, 2008).

\section{Division of Roles among Students}

After having students define their objectives, a total of 79 students participated in this project, from 6 different classes and 3 different grades. As all of them could not be under one leader, four different roles for each class were created, which had one coordinator who was helped by an assistant coordinator. Each role varies accordingly, as explained below (Refaat, 2011). (See also organizational chart in appendix 2).

(i) The coordinator's role was to follow up with the leaders, remind group members of the required tasks according to the due dates, revise their work, give them feedback on their work and participate 
at the end in the assessment process. The coordinators served as the liaison between the class, the community and the service leader.

(ii) The coordinator's assistant's role was to attend all the meetings with the coordinator, follow up on the work's progress, prepare advertisement for the project that was hanged inside and outside the school, assist the groups during the exhibition and assess the groups' work during the exhibition.

(iii) The leader's role was to distribute the work among group members including himself, remind them of the required tasks as well as the objectives, visit the place and write a report on the actual status, as well as the planned one, revise the members' work, assess them during the application stage and present a report at the end to assess the participation of each member in all stages of the project.

(iv) The member's role was to work cooperatively with their group leader, do the tasks assigned to them from the leader, participate in collecting donations, prepare the portfolio, work on the application day, prepare the booth, explain the project to the visitors in the exhibition and present their feedback to the leader (GPIS, 2008).

\section{Project's Lifecycle}

The project was divided into four stages, namely:

(i) The planning stage

(ii) The application stage

(iii) The reflection and feedback stage

(iv) The assessment stage

While all group members were involved in the planning, application, reflection and feedback stages, only the coordinators and leaders were involved in the assessment stage. Mrs. Refaat -the service leader - played a major role in facilitating the project's deployment. She devised a set of tools and instruments to help organize and deliver the needed results.

\section{(i)The Planning Stage}

(a) Group leaders had to meet with their members, elaborate on their roles through a detailed job description including their duties and responsibilities after making their first visit to the Mostawsaf and to some of the poor families in their houses (who are actually the main beneficiaries from the Mostawsaf) to study their health needs. Such meetings took place in the students' assembly hours.

(b) Following each meeting, minutes of meetings were taken to discuss the meeting's objectives, ideas discussed and meeting decisions.

(c) After the first visit to the clinic, the leader then presented a report on the detailed description of the situation, areas of improvements and suggested solutions.

(d) Leaders then presented a detailed plan on what to be done, who is doing it, when, where and how much it will cost and the desired results.

\section{(ii)The Application Stage}

This stage included all the work itself and actions involved, like regular meetings with the poor locals living in the area to be familiar with their health problems and priorities; fund raising through bake sales, garage sales, car wash, baby sitting and exhibition; the different tasks done by all class members like buying needed materials and tools, cleaning the place and furnishing the Mostawsaf. 


\section{(ii)The Reflection Stage}

In the reflection stage, each student in class (coordinator, assistant coordinator, leader and member) was required to write a reflection report recalling his/her experience for the action he/she was involved in , own strength and weakness or problems encountered and how to overcome these problems as well as the lessons learnt out of that experience. In the reflection stage, each person not only assesses and writes a report about himself but also about his direct supervisor and his subordinates.

The following actions took place in the reflection stage:

(a) Coordinators evaluate themselves and their group leaders and assistant leaders and they are also evaluated by the school community and service leader.

(b) Leaders then evaluate their coordinators and assistant coordinators and their group members.

(c) Group members then evaluate their leaders, coordinators, community and service leader and themselves (GPIS, 2008).

\section{(iv)The Assessment Stage}

This is the last stage of the four-staged lifecycle, on which Mrs Iman Refaat, gives her final assessment report about each member in class, after looking at their self-assessment and the assessment of their supervisor and subordinates through a 'Rubric' form which she designed. The assessment criteria differ with the difference in role. For example, coordinators assess leaders on social intelligence, organization and punctuality....etc. Leaders assess members on work and time management criteria. Assistant coordinators assess their coordinators on duties and responsibilities. Mrs. Refaat then records all the students' assessments in a report form. Each group had to prepare a portfolio including all the work they did, organized with the same sequence of the stages of the project.

\section{Lessons Learnt}

From the above, it is clear the Mostawsaf project is a successful example of how to manage community-based projects, some of the lessons learnt that can be deduced from Greenland's experience are:

(i) 360c appraisal method is an integral component of the HR management process: The self-evaluation and evaluation by other team members helped in diagnosing the weakness of each student to be able to take corrective action.

(ii) Reflection phase is an important phase that acts as a catalyst for continuous improvements: Students had to record their own reflection and assessment of themselves, their supervisors and subordinates after each task, define their strength and weaknesses and work on overcoming any of these weaknesses. That on-going corrective action taken by students acted as a control tool that helped in achieving a better performance for the project.

(iii) Adequate time and effort should be spent in the planning stage: Defining SMART objectives before the actual implementation helped in yielding accurate results. Additionally, during the planning stage, students were involved in defining the $5 \mathrm{Ws}$ of what to be done exactly with a clarification of each person's role, responsibilities and duties, when to do it, where to do it, how to do it, and how much it will cost to do it.

(iv) Continuous follow-ups and feedback is of paramount importance: The coordinators and the leaders continuous follow-ups and feedback to their members acted as an accurate instrument to stir the group's efforts in the correct direction and to make sure that everybody is focused on their 
tasks. It also helped in building the group commitment, enthusiasm and motivation.

(v) Encourage students to think out of the box: Students used creative ways to market the project (using the stairs and corridors for advertising for the project) and innovative fundraising ideas for the Mostawsaf (garage, bake sales). These practices made the project fun and motivated the students to work in groups to achieve a common goal.

(vi) Encourage and support the entrepreneurial spirit: The decision of the Mostawsaf was the students' idea; they felt like the real owners of the project, where the school was facilitating and supporting their jobs. This spirit helped in achieving a strong momentum to the project.

\section{Conclusion}

A developing country like Egypt has many challenges ahead, especially after the January 2011 revolution, as government efforts and public budgets are not sufficient to solve all the serious accumulated problems the country faces. The contribution of the business community is therefore very important especially in the development of rural and poor areas abundant across Egypt, not only through job creation, but also through venues like different developmental projects in various areas (like education, healthcare, environment ... etc.). The best approach is a win-win approach, where all stakeholders benefit. Developmental projects for these poor areas are not only of direct benefit to the locals, but it is of both direct and indirect benefit to business, and more importantly, it is of direct benefit to the country at large.

The school has since initiated a second educational project in the Sheikh Zayed area, and has a number of other similar projects in the pipeline. The positive experience of this school and the dissemination of similar success stories on the national and regional levels will help encourage the multiplication of such efforts and would make a positive contribution for development and poverty alleviation which governments can't assume on their own. We wish new Egypt a bright future, it is a country with a great potential, so together with the cooperation among all stakeholders, including the business community, we can together realize social and economic justice. But the question always remains: how can the Greenland success story for social responsibility be replicated by organizations in the MENA region for sustainable development in a winwin relationship with the local community?

\section{Acknowledgment}

- A special thanks goes to all Green Land International School team who were very supportive throughout the whole stages of the case writing, specially Architect Mokhtar Mokhtar and Ms. Iman Refaat for their tremendous help.

- Another special thanks is also extended to the conference team from The American University in Cairo, El-Khazindar Business Research and Case Study: Dr.Ahmed Tolba, Ms. Nouran Maher for her great help in editing the case, Mr. Ahmed El-Banhawy and Ms. Rana Ahmed and other team members. And also to the conference team of the German University in Cairo, Business Research and Case Center Cluster (BSRC): Dr.Noha Bassiouni and other team members.

\section{References}

Ezzat, O. (2011, Sept. 29). Interview by A.Maher [Personal Interview]. Mostawsaf Community Work, Cairo.

Ezzat, T. (2012,2). Interview by A.Maher [Personal Interview]. Mostawsaf Community Work, Cairo.

GPIS. (Producer) (2007). GPIS Community \& Services 2006-2007 [brochure]. Cairo, Egypt. 
9 The MENA Journal of Business Case Studies

GPIS. (Producer) (2008). GPIS Charity Association 2007-2008 [flyer]. Cairo, Egypt.'

GPIS. (Producer) (2008). GPIS Charity Events [Printed documents]. Cairo, Egypt.

GPIS. (Producer) (2008). GPIS Community Work \& Services 2007-2008 [Documentary Film]. Cairo, Egypt.

International Baccalaureate Organization, IBO. international Baccalaureate Organization 2005-20012. Retrieved from http://www.ibo.org/general/who.cfm, (2012, Jan. 1).

Khalifa, L.(2011, Sept. 2). Interview by A.Maher [Personal Interview]. Mostawsaf Community Work, Cairo.

Refaat, I.(2011, Nov. 29). Interview by A.Maher [Personal Interview]. Mostawsaf Community Work, Cairo.

Wali, M.2011, Oct. 12). Interview by A.Maher [Personal Interview]. Mostawsaf Community Work, Cairo. 
Teaching Notes

Case of Green Land International School Community-Based Work in Imbaba, Egypt: A Success Story of Corporate Social Responsibility

\section{Brief Synopsis of the Case}

This case recalls the success story of Green Land International Baccalaureate (IB) School in the community-based work initiated by the school staff and students, their management process for the small charitable hospital or the 'Mostawsaf' serving the Geziret Mohamed community, the objective of which is to highlight the main lessons learnt that could serve as a model for business and corporations to replicate in other poor and deprived areas in the MENA region for sustainable development in a winwin relationship with the local community.

\section{Teaching Objectives}

The objective of this case is to provide students with a deep practical analysis and understanding for many of the management and public administration concepts related to human resource management, leadership and motivation, groups and teams, applications of the management functions (planning, organizing, directing and controlling) and understanding of social responsibility issues.

\section{Suggested Questions for Students}

1- If you were in decision-maker's position of Green land International Baccalaureate School, what would be your analysis of the situation described, and what actions would you take and why?

2- Explain the lessons learnt which led to the success of the clinic or Mostawsaf project with regards to: (i) Human Resource Management, (ii)Groups and Teams work, (iii) Leadership role and Motivation, (iv) Others.

3- Explain how was the management function (planning, organizing, directing and controlling) for the Mostawsaf project exercised?

4- Explain how can the Mostawsaf project with its organized management for social responsibility be replicated in our organizations in Egypt? What obstacles would be waiting for such projects? And how can we counteract the effect of these obstacles? 
11 The MENA Journal of Business Case Studies

\section{Appendix (1)}

Samples of the Students' Planning Stage for the Clinic/ Mostawsaf Project

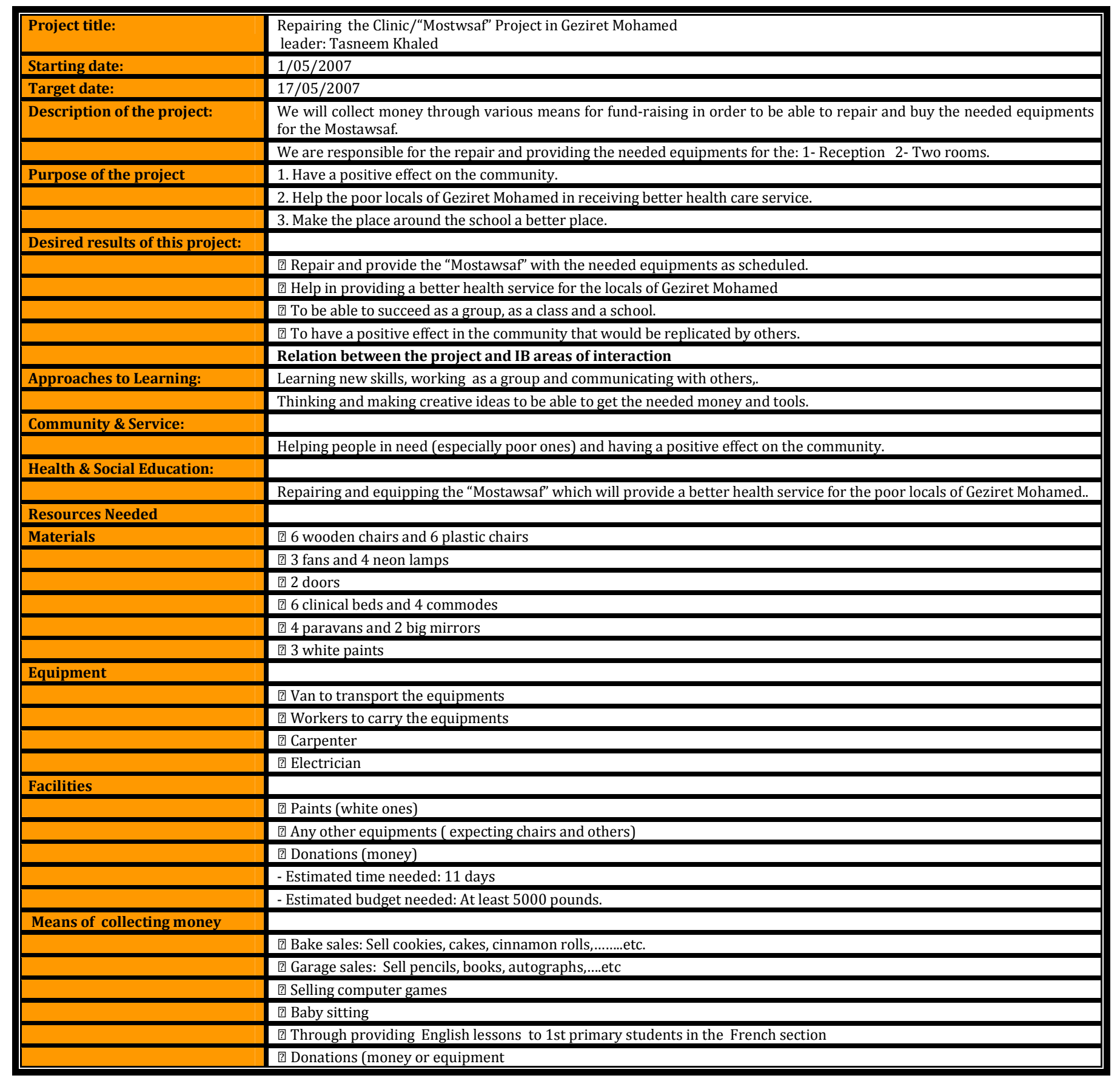


Students' Different Roles in Each Class for the Mostawsaf Project

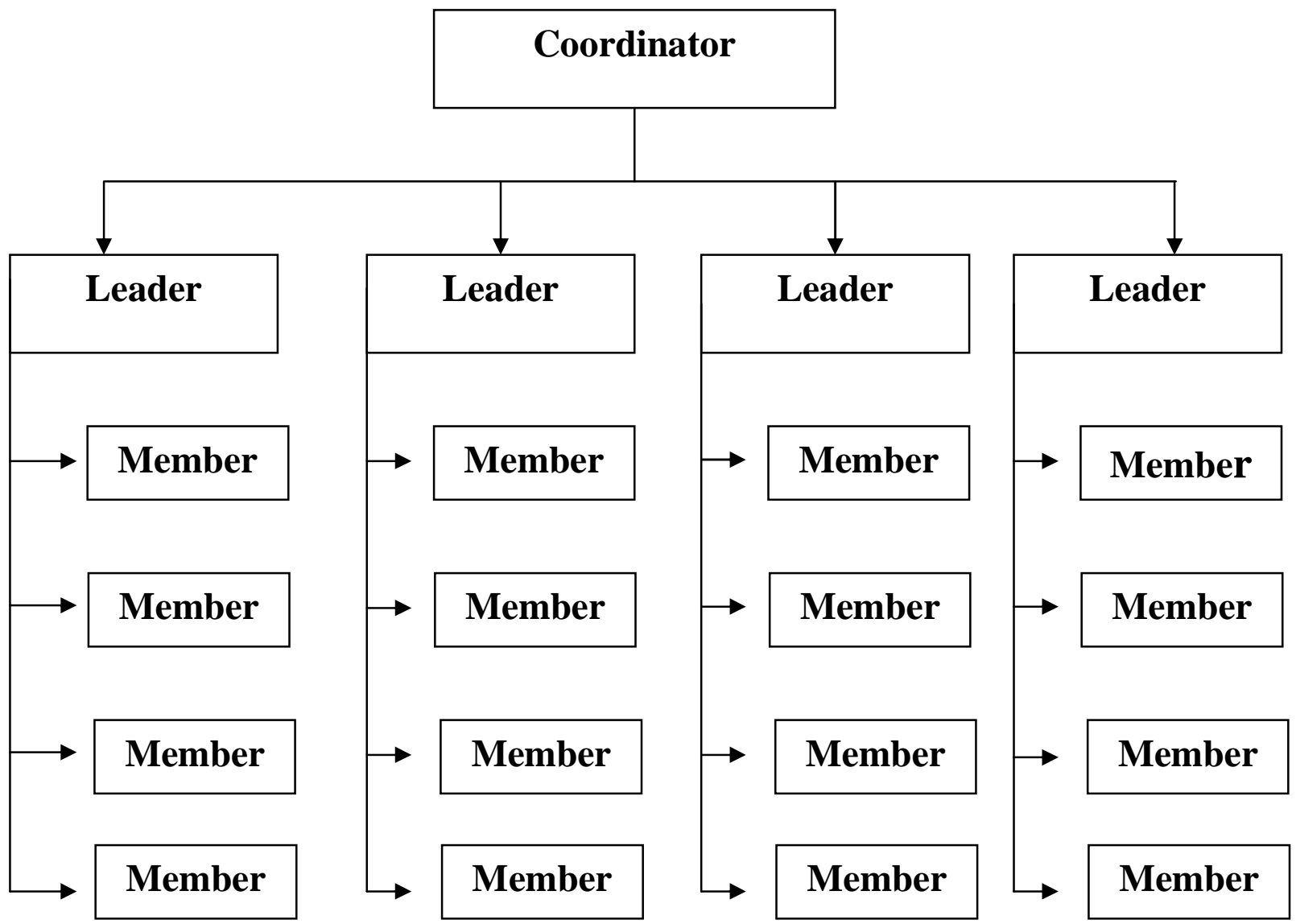

Appendix (3) Part A

Sample of a Student's Reflection and Feedback Stage

Leader's Reflection “Drive Yourself"

Community \& Service Project (C\&S): Mostawsaf Project

Leader's name: Omar Ezzat Class: MYP-4

(i) The Difficulties OurTeam Members Faced during the Project's Stages

(a) I think our team was able to overcome all difficulties in the different stages of the project. In the beginning of the project, the team had faced some difficulties with the budget. We had put our budget haphazardly without having estimated amounts from our fundraising sources. 
13 The MENA Journal of Business Case Studies

(b) Another difficulty that we had was the delivery of the needed tools to the school; although it was a bit hard for some of us in the beginning to lift some of the heavy bought stuff for the Mostawsaf from the school to the bus, we got used to it later by helping each other which was so much fun and excitement.

(c) In some stages, I have to admit that I found it is not worth delegating the tasks to the team members as that will involve lot of follow ups and sending reminders for simple tasks that I can take it all.

(ii) The Strengths I Showed during the Stages of the Project

(a) I learnt to be organized more than before, even if it didn't show but I felt it.

(b) I know exactly what is required from me as per my job description.

(c) Another strength that I showed was that I didn't treat any of the group members badly like in previous projects. I wasn't stressed since everything was clear, planned and well organized (thanks God and thanks to Ms. Iman Refaat).

\section{(iii) The Weaknesses I Showed during the Stages of the Project}

Sometimes I did not meet deadlines as I left things till the last minute. I wasn't worried or frustrated that the due date was near.

(iv) Changes I Plan to Do in Future for the Community Projects

(a) Before joining any of these community projects, I think I should give more time to planning.

(b) I also must do more effort to make everything clear for the members before hand.

(v) Comments about the Project in General

I would consider this Mostawsaf project an excellent support for the poor locals, hoping to have similar future projects, because the more we will be involved in these kinds of projects, the more we will gain experience and perform better. I think this is one of the very helpful projects that we performed within the IB community and service program. 


\section{Appendix (3) Part B}

Sample of the Leader's Self-Assessment on His Performance during the Stages of the Project.

Community \& Service Project: Mostawsaf Project

Leader's name: Omar Ezzat

Class: MYP-4

\begin{tabular}{|c|c|}
\hline Task & Due Date \\
\hline $\begin{array}{l}\text { The leader assesses his performance as per his written job description. } \\
\text { Receive the distribution of work and the minutes of meeting forms from } \\
\text { the coordinator. }\end{array}$ & $23 / 3 / 09$ \\
\hline $\begin{array}{l}\text { Meet members to discuss their job descriptions and the distribution of tasks } \\
\text { among them. Fill the minutes of meeting form. }\end{array}$ & $25 / 3 / 09$ \\
\hline Send the minutes of meeting to the coordinator & $27 / 3 / 09$ \\
\hline $\begin{array}{l}\text { Receive the coordinator's report on their meetings with the locals of } \\
\text { Geziret Mohamed to investigate about their health problems. } \\
\text { service } p\end{array}$ & $28 / 3 / 09$ \\
\hline $\begin{array}{l}\text { Prepare a camera, a report form and any other needed } \\
\text { tools for the visit. }\end{array}$ & $31 / 3 / 09$ \\
\hline $\begin{array}{l}\text { Visit the poor local families of Geziret Mohamed and take photos } \\
\text { For their houses to report their deteriorating health environment. }\end{array}$ & $2 / 4 / 09$ \\
\hline Send the filled report to the coordinator. & $4 / 4 / 09$ \\
\hline Receive the fundraising form from the coordinator & $4 / 4 / 09$ \\
\hline $\begin{array}{l}\text { Meet members to discuss the detailed plan for their tasks, discuss the local } \\
\text { health needs, estimated budget and their plans for fundraising according to } \\
\text { the report filled during the visit. }\end{array}$ & $5 / 4 / 09$ \\
\hline Send the detailed plan of work to the coordinator. & $6 / 4 / 09$ \\
\hline Send the fundraising plan to the coordinator. & $6 / 4 / 09$ \\
\hline $\begin{array}{l}\text { Present a CD with all the photos taken during the members' local visits and } \\
\text { the meetings to the coordinator.(Write on the CD: title of the project - } \\
\text { leader's name - } \\
\text { date - A: Planning stage ). }\end{array}$ & $8 / 4 / 09$ \\
\hline
\end{tabular}




\section{Appendix (3) Part B}

Sample of the Leader's Self-Assessment on His Performance during the Stages of the Project.

Community \& Service Project: Mostawsaf Project

Leader's name: Omar Ezzat

Class: MYP-4

\begin{tabular}{|l|l||}
\hline Stage 2: Fundraising \& Application & Due Date \\
\hline Task & $7 / 5 / 09$ \\
\hline $\begin{array}{l}\text { Work on the fundraising activities. } \\
\text { Take photos during all activities of fundraising. }\end{array}$ & $10 / 5 / 09$ \\
\hline $\begin{array}{l}\text { Send the final fundraising form to the coordinator. } \\
\text { Buy the local's medical needs for the members' next visit. The } \\
\text { assistant/coordinator must accompany the group. }\end{array}$ & $10 / 5 / 09$ \\
\hline \begin{tabular}{l} 
Receive any related documents from the coordinator. \\
\hline $\begin{array}{l}\text { Send a copy of the signed documents to the coordinator and file the original } \\
\text { Copy. }\end{array}$
\end{tabular} & $13 / 5 / 09$ \\
\hline $\begin{array}{l}\text { Present a CD with all photos taken during the application stage to the } \\
\text { Application stage.) }\end{array}$ & \\
\hline
\end{tabular}

